\title{
Reduced risk of chronic GVHD by low-dose rATG in adult matched sibling donor peripheral blood stem cell transplantation for hematologic malignancies
}

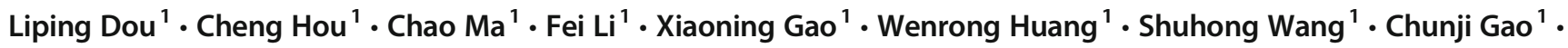 \\ Li Yu ${ }^{1} \cdot$ Daihong Liu ${ }^{1}$ (D)
}

Received: 16 September 2019 / Accepted: 3 December 2019 / Published online: 11 December 2019

(C) The Author(s) 2019

\begin{abstract}
The optimal rabbit anti-thymocyte globulin (rATG) graft-versus-host disease (GVHD) prophylaxis regimen in matched sibling donor peripheral blood stem cell transplantation (MSD-PBSCT) remains to be elucidated. In this prospective study, we used lowdose rATG for GVHD prophylaxis in patients or donors aged $\geq 40$ years with hematological malignancies receiving MSDPBSCT. rATG was administered to 40 patients at an intravenous dose of $5 \mathrm{mg} / \mathrm{kg}$ divided over day 5 and day 4 before graft infusion. No graft failure occurred. Median times to leukocyte engraftment and platelet engraftment were 11.0 days and 13.9 days. The cumulative incidence of grades 2-4 and grades 3-4 acute GVHD at day +100 was $30.0 \%$ and $2.6 \%$. The 2-year cumulative incidence of extensive chronic GVHD and severe chronic GVHD was $11.4 \%$ and $14.7 \% .93 .5 \%$ (29/31) of patients had discontinued immunosuppressive medication within 3 years after transplantation. The 2-year cumulative incidence of transplant-related mortality (TRM) and relapse was $14.0 \%$ and $22.6 \%$. The cumulative incidence of cytomegalovirus reactivation, Epstein-Barr virus reactivation, and fungal infection was 22.3\%, 12.9\%, and 12.5\%. Kaplan-Meier estimates for overall survival, disease-free survival, and GVHD-free and relapse-free survival 3 years after transplantation were $68.9 \%, 68.9 \%$, and $54.0 \%$. rATG for GVHD prophylaxis is tolerable and efficacious at a $5 \mathrm{mg} / \mathrm{kg}$ total dose administered over 2 days (days -5 to -4 ) in patients receiving allogeneic MSD-PBSCT.
\end{abstract}

Keywords ATG $\cdot$ Stem cell transplantation $\cdot$ Peripheral blood $\cdot$ Graft-versus-host disease $\cdot$ Relapse

\section{Introduction}

Chronic graft-versus-host disease (GVHD) increases the risk for long-term morbidity, poor quality of life, and death after matched sibling donor (MSD) stem cell transplantation [1]. Risk factors for chronic GVHD (cGVHD) include receipt of a peripheral blood stem cell graft and a history of acute GVHD (aGVHD) [2]. There is an urgent need to reduce the incidence of severe cGVHD and improve the quality of life in patients who have undergone MSD peripheral blood stem cell transplantation (MSD-PBSCT) [3]. We have reported that rabbit anti-thymocyte globulin (rATG) (Sanofi, Paris, France) may

$\overline{\text { Liping Dou, Cheng Hou and Chao Ma contributed equally to this work. }}$

Daihong Liu

daihongrm@163.com

1 Department of Hematology, Chinese PLA General Hospital, Fuxing Road 28th, Haidian District, Beijing 100853, China effectively and safely reduce the incidence and severity of cGVHD in patients receiving myeloablative conditioning before peripheral blood stem cell transplantation from haploidentical donors [4]. The 3-year cumulative incidence of extensive and severe cGVHD was $41.5 \%$ and $21.2 \%$ in patients receiving MSD-PBSCT (without rATG) compared with $17.1 \%(P=0.017)$ and $5.8 \%(P=0.049)$ in patients receiving stem cells from haploidentical donors [4]. Our ATG GVHD prophylaxis regimen in unmanipulated haploidentical PBSCT includes rATG given at a dose of $10 \mathrm{mg} / \mathrm{kg}$ over 4 days (days -5 to -2 ) before graft infusion. The incidence of Epstein-Barr virus (EBV) and cytomegalovirus (CMV) antigenemia and EBV-associated post-transplantation proliferative disease (PTLD) was higher in patients receiving stem cells from haploidentical donors compared with that of patients receiving MSD-PBSCT. Donor age $\geq 40$ years vs. younger donors was associated with a higher incidence of aGVHD grades $2-4(P=0.02)$ and treatment-related mortality (TRM) $(P=0.022)[4]$. 
The use of rATG is a promising strategy for GVHD prophylaxis [5-11]. However, engraftment, immune reconstitution, and GVHD prevention must be carefully balanced. The optimal ATG regimen for GVHD prophylaxis in MSDPBSCT remains to be elucidated [8]. Due to a high incidence of cGVHD in patients or donors aged $\geq 40$ years, rATG was prospectively added to the preparative regimen in MSDPBSCT. In this prospective study (ClinicalTrials.gov Identifier: NCT02677181), we investigated the feasibility of using low-dose rATG (Sanofi, Paris, France: preparation containing polyclonal immunoglobulins obtained from hyperimmune sera of rabbits immunized with human thymocytes) for GVHD prophylaxis in patients or donors aged $\geq 40$ years with hematological malignancies receiving MSD-PBSCT, compared with no use of rATG in patients or donors aged 14 to 40 years. rATG was administered at an intravenous dose of $5 \mathrm{mg} / \mathrm{kg}$ divided over day 5 and day 4 before graft infusion, which is half of the dose used by our group to reduce the risk of severe aGVHD in patients receiving hematopoietic stem cell transplantation without ex vivo $\mathrm{T}$ cell depletion from haploidentical donors [8].

\section{Methods}

This study was conducted in accordance with the principles of the Declaration of Helsinki and approved by the Ethics Committee of the Chinese People's Liberation Army (PLA) General Hospital. All patients provided written informed consent.

\section{Study design}

Consecutive patients with myelodysplastic syndrome (MDS)/ acute leukemia (AML/ALL) who received allogeneic MSDPBSCT with low-dose rATG (Sanofi, Paris, France) in combination with cyclosporine, mycophenolate, and short-term methotrexate for GVHD prophylaxis at our center between June 1, 2013, and August 1, 2019, were eligible for this study. First-line GVHD prophylaxis for HLA-identical sibling transplant patients or donors aged 40 to 65 years was low-dose rATG (Sanofi, Paris, France) in combination with cyclosporine, mycophenolate, and short-term methotrexate. First-line GVHD prophylaxis for HLA-identical sibling transplant patients or donors aged 14 to 40 years was cyclosporine, mycophenolate, and short-term methotrexate without rATG. All patients received myeloablative conditioning regimens. The conditioning regimen for MSD-PBSCT consisted of busulfan (Otsuka Pharmaceutical Company, China; $3.2 \mathrm{mg} / \mathrm{kg} / \mathrm{day}$ intravenously, days -10 to -8 ), carmustine (Jinyao Tianjin Pharmaceutical Company, China; $250 \mathrm{mg} / \mathrm{m}^{2}$ intravenously, day -5), cytarabine (Pfizer Pharmaceutical Company, USA; $2 \mathrm{~g} / \mathrm{m}^{2} /$ day intravenously, days -7 to -6 ), and cyclophosphamide (Baxter Pharmaceutical Company, USA; $60 \mathrm{mg} / \mathrm{kg} /$ day intravenously, days -4 to -3 ).

Inclusion criteria were (1) patients or donors aged 14 to 65 years; (2) diagnosed with acute leukemia or myelodysplastic syndrome; and (3) indicated for MSDPBSCT.

The number of CD34-positive cells and lymphocyte subpopulations in the graft was analyzed. Multi-parameter flow cytometry was performed [9]. Median lymphocyte counts stratified into $\mathrm{CD}^{+}, \mathrm{CD}^{+}, \mathrm{CD}^{+}$, and $\mathrm{CD} 56 / \mathrm{CD} 16^{+}$subpopulations were determined (Wilcoxon rank sum test).

\section{HLA matching and graft selection}

Patients and donors were typed by means of high-definition PCR Luminex and sequence-based typing methods at HLAA, HLA-B, HLA-C, DRB1, and DQB1 [10]. All pairs were matched at these loci.

\section{rATG and GVHD prophylaxis}

Mobilized peripheral blood stem cells were transplanted [11, 12].

Patients in the ATG group were treated with $\mathrm{rATG}$ $1.5 \mathrm{mg} / \mathrm{kg}$ for $4-6 \mathrm{~h}$ on day -5 and $\mathrm{rATG} 3.5 \mathrm{mg} / \mathrm{kg}$ for 4 $6 \mathrm{~h}$ on day -4 for a total dose of rATG $5 \mathrm{mg} / \mathrm{kg}$ prior to transplant.

Patients in both groups received cyclosporine $3 \mathrm{mg} / \mathrm{kg}$ intravenously from day -10 until oral refeeding, targeting minimum concentration levels of 150 to $200 \mathrm{ng} / \mathrm{mL}$ for the first month. After 6 months, the dose of cyclosporine was tapered by $25 \%$ every 2 weeks in all patients except for those who had post-transplant relapse, in which case, the dose of cyclosporine was tapered after relapse. Tacrolimus was used in cases of cyclosporine intolerance or toxicity. Methotrexate $15 \mathrm{mg} / \mathrm{m}^{2}$ was administered on day +1 , and methotrexate $10 \mathrm{mg} / \mathrm{m}^{2}$ was administered on days $+3,+6$, and +11 . Mycophenolate mofetil $500 \mathrm{mg}$ was administered orally twice daily from days -10 to +30 .

Antimicrobial and antiviral prophylaxis was routinely administered. Blood samples were tested for EBV and CMV using polymerase chain reaction (PCR) testing $[13,14]$.

\section{GVHD therapy}

All aGVHD patients received a total daily dosage in two divided doses of methylprednisolone $2 \mathrm{mg} / \mathrm{kg} /$ day for 7 consecutive days, followed by a gradual reduction in dose, and a taper over 8 weeks $[15,16]$. 


\section{Immune monitoring}

Immune reconstitution after transplantation was studied in a subset of patients who consented to have peripheral blood samples collected on days $+30,+60,+90,+180,+240$, and +360 . Multi-parameter flow cytometry was performed [9]. Median lymphocyte counts stratified into $\mathrm{CD}^{+}, \mathrm{CD}^{+}$, $\mathrm{CD}^{+}$, and $\mathrm{CD} 56 / \mathrm{CD} 16^{+}$subpopulations were determined at each time point (Wilcoxon rank sum test) and analyzed with time-dependent multivariable Cox proportional hazards regression models.

\section{Definitions and end points}

All surviving patients were followed-up from the date of transplantation to August 1, 2019. Days before graft infusion were documented as "-,", and days after last stem cell infusion were documented as ".$+ "$

Primary endpoints were incidence of cGVHD, TRM, and relapse. Secondary endpoints were engraftment, incidence of aGVHD, overall survival (OS), disease-free survival (DFS), and GVHD-free and relapse-free survival (GRFS). Only patients with successful engraftment after transplantation were included in the aGVHD analysis. Patients who survived at least 100 days after transplantation were included in the cGVHD analysis $[9,15,16]$. The date of neutrophil recovery after transplantation was defined as the first of 3 consecutive days with an absolute neutrophil count $>0.5 \times 10^{9} / \mathrm{L}$ [17] The date of platelet recovery after transplantation was defined as the first of 7 consecutive days with an absolute platelet count $>20 \times 10^{9} / \mathrm{L}$ without the aid of transfusion.

Patients were assigned a disease risk using the Disease Risk Index as previously described [18]. Diagnosis and grading of aGVHD and cGVHD were performed according to standard criteria [16]. cGVHD was classified as "limited" or "extensive" according to the Seattle criteria $[15,16]$. cGVHD was classified as "mild" or "moderate" or "severe" according to the National Institutes of Health (NIH) criteria $[15,16]$. OS was defined as the time from transplantation to death from any cause. DFS was defined as survival with no evidence of relapse or disease progression. Relapse was defined as the presence of peripheral blood blast or $>5 \%$ bone marrow blasts and/or reappearance of underlying disease. GRFS was defined as the time onset of grade 3 to 4 aGVHD, moderate to severe cGVHD, or relapse/disease progression/death. TRM was defined as death without evidence of relapse or disease progression, with relapse as a competing event. Quality of life in survivors was measured with the Karnofsky Performance Status Scale.

\section{Statistical analysis}

Statistical analysis was performed using R statistical software (cmprsk package) and SPSS 20.0 Treatment group comparisons were performed using chi-square tests for categorical data and Mann-Whitney $U$ tests for continuous variables. Cumulative incidence was estimated for TRM, relapse, and GVHD (grades 2 to 4 or 3 to 4 aGVHD and cGVHD of any severity or extensive). The probability of developing aGVHD or cGVHD was depicted by determining the cumulative incidence with aGVHD or cGVHD without relapse as competing risks. Gray's test was used to assess the difference between treatments. The 95\% CI for the differences was calculated using the Wilson score method. OS, DFS, and GRFS were computed with the Kaplan-Meier method. Univariate and multivariate analyses were performed with Cox proportional hazards regression analysis.

Prognostic factors were diagnosis, patient age at transplantation, donor-recipient sex matching, status at time of transplantation (complete remission versus other), time from diagnosis to transplantation ( $<6$ months vs. $\geq 6$ months), nucleated and $\mathrm{CD} 34^{+}$cells dose $/ \mathrm{kg}$, and blood group and compatibility. Predictors with $P$ values $<0.2$ on univariate analyses were included in the multivariate analysis. $P<0.05$ was considered significant.

\section{Results}

\section{Patient characteristics}

A total of 72 consecutive patients were enrolled in this study (Table 1). Of these, 2 patients were excluded because of progressive disease (1 patient) or the donor withdrew (1 patient). The final analysis included 70 patients ( 40 patients in the ATG group and 30 patients in the no-ATG group). At the time of transplantation, the patients with AML/ALL were in complete remission (CR1) following conventional therapy or salvage therapy, while the patients with MDS-EB-2 were untreated. Median follow-up was 996 days (range, 271-1825 days). Patients and donors in the ATG group were older than those in the no-ATG group (patients: ATG group 46.9 years vs. noATG group 29.7 years; donors: ATG group 48.8 years vs. noATG group 29.8 years). No difference was observed in other baseline clinical characteristics between the two groups, including the percentage of high-risk disease according to the Disease Risk Index [18].

\section{Graft failure and engraftment}

Patients in the ATG group received G-CSF mobilized PBSC with MNCs 9.2 (6.2-14.6) $\times 10^{8} / \mathrm{kg}$ and CD34 $4^{+}$cells $3.6(1.6-$ $8.2) \times 10^{6} / \mathrm{kg}$. Patients in the no-ATG group received MNCs 
Table 1 Clinical features of SCT recipients and donors

\begin{tabular}{|c|c|c|c|}
\hline Characteristic & ATG group & No ATG group & $P$ value \\
\hline No. of patients & 40 & 30 & \\
\hline Patient's age, median, years (range) & $46.9(40-62)$ & $29.7(12-39)$ & 0.001 \\
\hline Gender & & & 0.334 \\
\hline Male & 22 & 13 & \\
\hline Female & 18 & 17 & \\
\hline Time between diagnosis and stem-cell transplantation-days & & & 0.055 \\
\hline Median (range) & $172.9(50-344)$ & $313(59-2014)$ & \\
\hline Diagnosis-no. $(\%)$ & & & 0.431 \\
\hline Acute myeloid leukemia & 17 & 18 & \\
\hline Acute lymphoid leukemia & 14 & 6 & \\
\hline MDS & 9 & 6 & \\
\hline Disease status at transplantation & & & 0.323 \\
\hline Untreated MDS-AML & 9 & 5 & \\
\hline CR1 & 31 & 25 & \\
\hline High cytogenetic risk-no. (\%) & $18(45.0 \%)$ & $10(33.3 \%)$ & 0.725 \\
\hline Disease Risk Index — no./total no. (\%) & & & 0.268 \\
\hline Low & $4(10.0 \%)$ & $2(6.7 \%)$ & \\
\hline Intermediate & $26(65.0 \%)$ & $15(50.0 \%)$ & \\
\hline High & $10(25.0 \%)$ & $13(43.3 \%)$ & \\
\hline Very high & $0(0.0 \%)$ & $0(0.0 \%)$ & \\
\hline Conditioning regimen & & & 0.685 \\
\hline Modified Bu/Cy & 38 & 29 & \\
\hline Modified Bu/Flu & 2 & 1 & \\
\hline Donor's age, median, years (range) & $48.8(40-61)$ & $29.8(11-39)$ & 0.001 \\
\hline Donor-recipient $\mathrm{ABO}$ match & & & 0.454 \\
\hline Match & 18 & 21 & \\
\hline Major mismatch & 6 & 4 & \\
\hline Minor mismatch & 4 & 5 & \\
\hline Bidirectional mismatch & 3 & 0 & \\
\hline Donor-recipient gender match & & & 0.859 \\
\hline Female to male & 14 & 12 & \\
\hline Female to female & 10 & 5 & \\
\hline Male to female & 10 & 7 & \\
\hline Male to male & 8 & 6 & \\
\hline \multicolumn{4}{|l|}{ Graft } \\
\hline MNCs, median, $\times 10^{8} / \mathrm{kg}$ (range) & $9.2(6.2-14.6)$ & $8.0(5.1-12.6)$ & 0.063 \\
\hline $\mathrm{CD} 4^{+}$, median, $\times 10^{6} / \mathrm{kg}$ (range) & $3.6(1.6-8.2)$ & $3.6(2.3-9.3)$ & 0.547 \\
\hline B cell, median, $\times 10^{6} / \mathrm{kg}$ (range) & $21.1(14.3-34.6)$ & $19.9(7.9-29.4)$ & 0.669 \\
\hline $\mathrm{T}$ cell, median, $\times 10^{6} / \mathrm{kg}$ (range) & $84.6(11.8-265.4)$ & $93.3(46.5-248.7)$ & 0.710 \\
\hline $\mathrm{CD} 4^{+} \mathrm{T}$ cell, median, $\times 10^{6} / \mathrm{kg}$ (range) & $46.1(0.3-171.5)$ & $49.3(1.3-133.8)$ & 0.818 \\
\hline $\mathrm{CD}^{+} \mathrm{T}$ cell, median, $\times 10^{6} / \mathrm{kg}$ (range) & $33.1(4.2-72.7)$ & $36.9(1.8-115.3)$ & 0.692 \\
\hline NK cell, median, $\times 10^{6} / \mathrm{kg}$ (range) & $14.8(0.2-97.6)$ & $9.2(0.2-25.9)$ & 0.576 \\
\hline
\end{tabular}

$A T G$, anti-T lymphoglobulin; $C R$, complete remission; $M D S-A M L$, AML evolution from MDS; $N H L$, non-Hodgkin lymphoma; $N R$, non-remission; $S C T$, hematopoietic stem cell transplantation; $W B C$, white blood cell; $M N C$, mononuclear cells; $N K$ cell, natural killer cell

$8.0(5.1-12.6) \times 10^{8} / \mathrm{kg}$ and CD34 ${ }^{+}$cells $3.6(2.3-9.3) \times 10^{6} /$ $\mathrm{kg}$. There were no differences in the counts of the lymphocyte subpopulations in the grafts between the two groups (Table 1).
No graft failure was observed. One patient (3.2\%) in the ATG group died of severe infection on day +14 before engraftment. One patient (3.3\%) in the no-ATG group developed prolonged 
isolated thrombocytopenia and died of aGVHD on day +71 without platelet engraftment. Sustained myeloid engraftment with full donor chimerism was achieved in all tested patients. Median times to leukocyte engraftment and platelet engraftment in the ATG group were 11.0 days (range, 8 to 16 days) and 13.9 days (range, 9 to 30 days), respectively (Table 2). Median times to leukocyte engraftment and platelet engraftment in the no-ATG group were 11.0 days (range, 9 to 15 days) and 15.8 days (range, 9 to 22 days), respectively (Table 2).

\section{Acute and chronic GVHD}

In the ATG group, 39 patients were engrafted and survived. Among these, 15 (38.5\%) patients developed grades 1-4 aGVHD (grade 1, $n=2$; grade 2, $n=12$; grade $3, n=1$ ) at a median 30 (range, 13-85) days after transplantation. The cumulative incidence of grades $2-4$ and grades $3-4$ aGVHD was $30.0 \%$ (95\% CI, $18.0-50.5 \%$ ) and $2.6 \%$ (95\% CI, $2.5-18.6 \%$ ) at day +100 , respectively (Fig. 1a). On univariate analysis, no risk factors were associated with the occurrence of $>$ grade 2 aGVHD (Table 2). Two patients with aGVHD died. Causes of death were disease relapse ( $n=1$, grade $2 \mathrm{aGVHD}$ ) and pneumonia ( $n=1$, grade 3 aGVHD).

There was no difference in the incidence of aGVHD among the 69 patients who were engrafted and survived (39 patients in the ATG group vs. 30 patients in the no-ATG group). The cumulative incidence of grade $2-4$ aGVHD was $30.0 \%$ (95\% CI, $18.0-50.5 \%)$ in the ATG group and $40.0 \%$ (95\% CI, 22.4 $57.0 \%)$ in the no-ATG group at day $+100(P=0.355$; Fig. $2 a)$. The cumulative incidence of grade $3-4$ aGVHD was $2.6 \%$

Table 2 Rates of engraftment, infection, acute and chronic GVHD, and other complications after allogeneic peripheral blood stem cell transplantation from HLA-identical sibling

\begin{tabular}{|c|c|c|c|}
\hline Variable & ATG group $(n=40)$ & No ATG group $(n=30)$ & $P$ value \\
\hline Graft failure - no. (\%) & 0 & 0 & \\
\hline Prolonged isolated thrombocytopenia-no. $(\%)$ & 0 & 0 & \\
\hline \multicolumn{4}{|l|}{ Days to engraftment — median (range) } \\
\hline Absolute neutrophil count $\geq 0.5 \times 109 / \mathrm{L}$ & $11.0(8-16)$ & $11.0(9-15)$ & 0.517 \\
\hline Platelet count $\geq 20 \times 109 / \mathrm{L}$ & $13.9(9-30)$ & $15.8(9-22)$ & 0.710 \\
\hline Infectious complication-no. $(\%)$ & $15(37.5)$ & $12(40.0)$ & 0.018 \\
\hline Cytomegalovirus reactivation-no. $(\%)$ & $11(27.5)$ & $3(10.0)$ & 0.070 \\
\hline Epstein-Barr virus reactivation-no. (\%) & $5(12.5)$ & $1(3.3)$ & 0.039 \\
\hline Post-transplantation lymphoproliferative disorder-no. $(\%)$ & 0 & 0 & \\
\hline Acute GVHD within 100 days after transplantation-no. (\%) & $15(37.5)$ & $15(50.0)$ & 0.786 \\
\hline Overall grades of acute GVHD—no. (\%) & & & 0.453 \\
\hline 0 & $25(62.5)$ & $15(50.0)$ & \\
\hline 1 & $2(5.0)$ & $2(6.7)$ & \\
\hline 2 & $12(30.0)$ & $10(33.3)$ & \\
\hline 3 & $1(2.5)$ & $3(10.0)$ & \\
\hline 4 & $0(0)$ & $0(0)$ & \\
\hline $2-4$ & $13(32.5)$ & $13(43.3)$ & \\
\hline $3-4$ & $1(2.5)$ & $3(10.0)$ & \\
\hline Chronic GVHD & & & 0.153 \\
\hline \multicolumn{4}{|l|}{ Day of onset } \\
\hline Median (range) & $524(150-957)$ & $380(112-889)$ & \\
\hline Severity according to revised Seattle criteria - no. $(\%)$ & & & 0.033 \\
\hline Limited & $7(17.9)$ & $6(21.4)$ & \\
\hline Extensive & $6(15.4)$ & $9(32.1)$ & \\
\hline Severity according to NIH criteria-no. $(\%)$ & & & 0.085 \\
\hline Mild & 7 (17.9) & $4(14.3)$ & \\
\hline Moderate & $5(12.8)$ & $6(21.4)$ & \\
\hline Severe & $1(2.6)$ & $5(17.9)$ & \\
\hline
\end{tabular}

$A T G$, anti-T lymphoglobulin; $C R$, complete remission; $M D S-A M L$, AML evolution from MDS; $N H L$, non-Hodgkin lymphoma; $N R$, non-remission; $S C T$, hematopoietic stem cell transplantation; $W B C$, white blood cell; $M N C$, mononuclear cells

Chronic, limited, and extensive GVHD are defined according to the Seattle criteria

Chronic, mild, moderate, and severe GVHD are defined according the NHI criteria 
Fig. 1 Cumulative incidence of aGVHD, cGVHD, TRM, relapse, OS, and DFS after MSD-PBSCT with low-dose rATG in combination with cyclosporine, mycophenolate, and short-term methotrexate for GVHD prophylaxis.

GVHD, graft-versus-host disease; TRM, treatment-related mortality; OS, overall survival; DFS, disease-free survival a

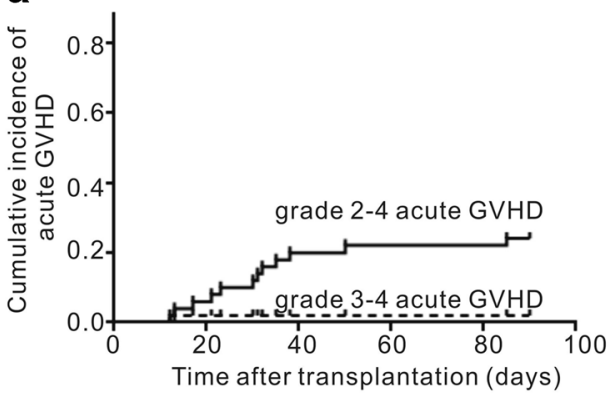

C

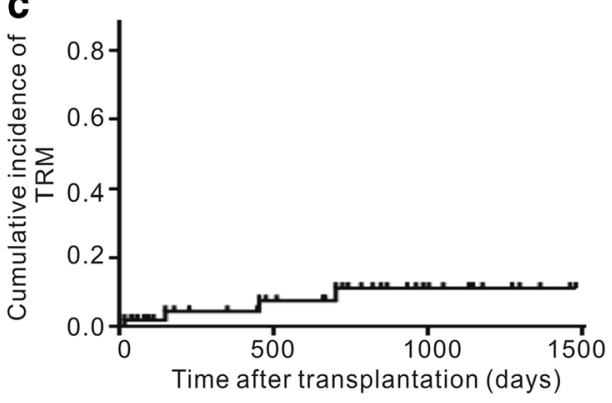

e

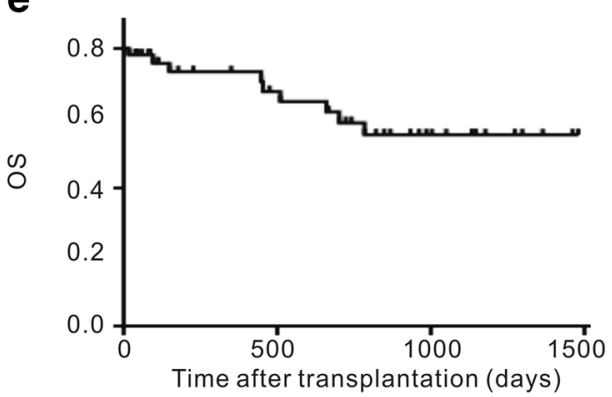

b

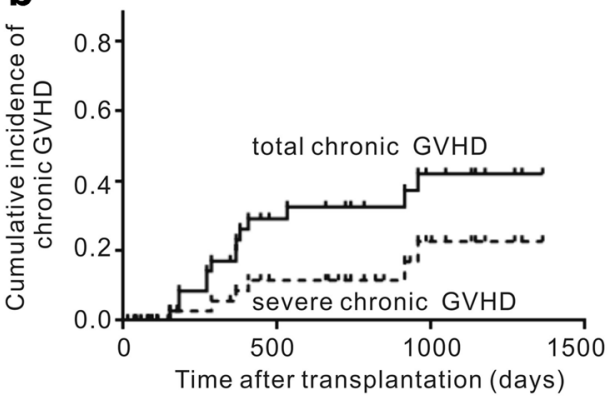

d

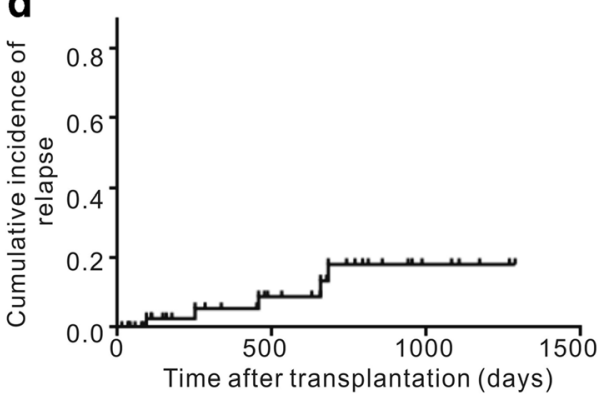

f

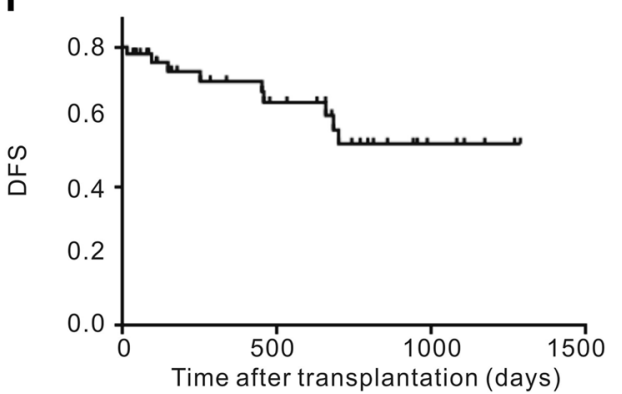

Fig. 2 Cumulative incidence of aGVHD and cGVHD after MSDPBSCT with low-dose rATG or no rATG in combination with cyclosporine, mycophenolate, and short-term methotrexate for GVHD prophylaxis. GVHD, graft-versus-host disease

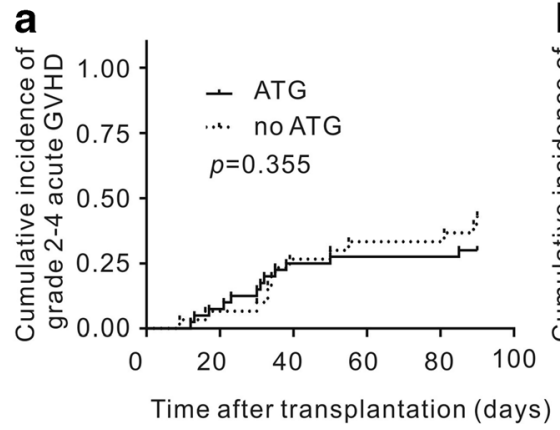

b
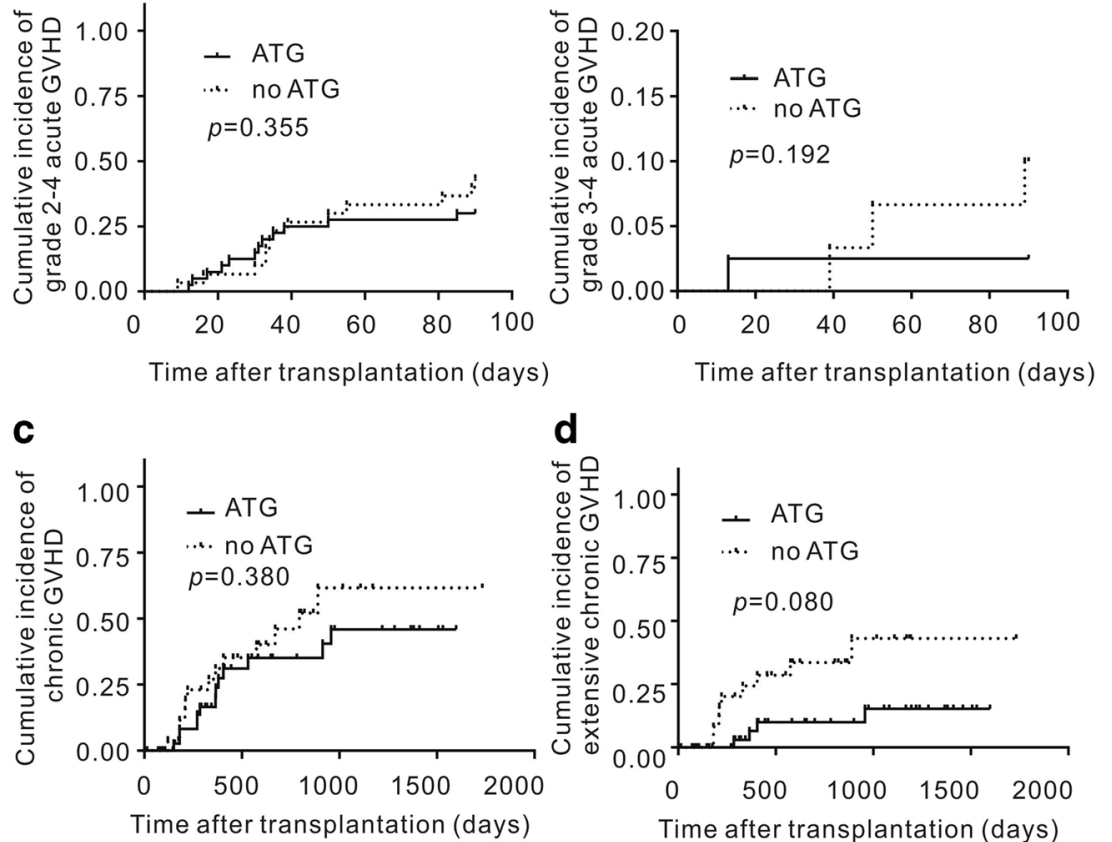


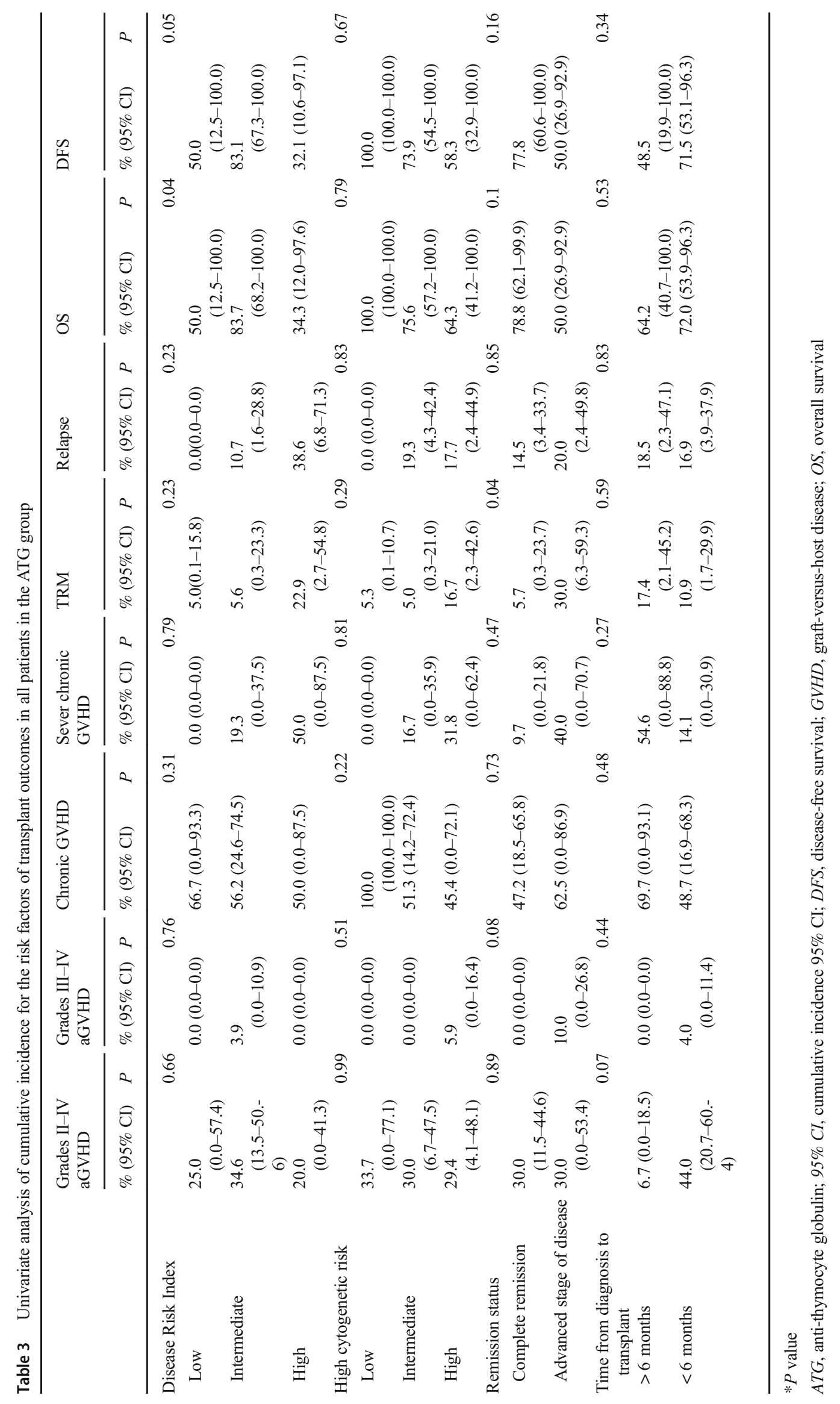


Table 4 Multivariate analysis of OS or DFS for the risk factors of transplant outcomes in all patients in the ATG group

\begin{tabular}{|c|c|c|c|}
\hline Event & HR & $95 \% \mathrm{CI}$ & $P$ \\
\hline \multicolumn{4}{|l|}{ OS } \\
\hline \multicolumn{4}{|l|}{ High Disease Risk Index } \\
\hline No & 1 & & \\
\hline Yes & 5.19 & $1.38-19.47$ & 0.01 \\
\hline \multicolumn{4}{|l|}{ DFS } \\
\hline \multicolumn{4}{|l|}{ High Disease Risk Index } \\
\hline No & 1 & & \\
\hline Yes & 5.29 & $1.41-19.88$ & 0.01 \\
\hline \multicolumn{4}{|l|}{ Chronic GVHD } \\
\hline \multicolumn{4}{|l|}{ Female donor and male recipient } \\
\hline No & 1 & & \\
\hline Yes & 60.43 & 2.72 to 134.62 & 0.01 \\
\hline \multicolumn{4}{|c|}{ Number of CD34 cells in the graft } \\
\hline Low (less than × 106/kg) & 1 & & \\
\hline High (more than $\times 106 / \mathrm{kg}$ ) & 0.54 & $0.31-0.92$ & 0.02 \\
\hline
\end{tabular}

(95\% CI, 2.5-18.6\%) in the ATG group and $10.0 \%$ (95\% CI, $2.5-23.9 \%)$ in the no-ATG group at day $+100(P=0.192$; Fig. $2 b)$. In the no-ATG group, 7 patients with aGVHD died. Causes of death were disease relapse $(n=4)$, thrombotic microangiopathy $(n=1)$, and pneumonia $(n=2)$.

In the ATG group, a total of 13 (32.5\%) patients developed cGVHD, with a median time to onset of +524 (range, $+150-957)$ days. Five of the 13 patients with cGVHD had preceding aGVHD. The 1-year, 2-year, and 3-year cumulative incidences of cGVHD were $25.1 \%$ (95\% CI, 19.6$26.8 \%$ ), $40.5 \%$ (95\% CI, 21.3-61.0\%), and 52.4\% (95\% CI, 31.0-70.0\%), respectively, and the 1-year, 2-year, and 3 -year cumulative incidences of severe cGVHD were $7.6 \%$ (95\% CI, 7.0-14.9\%), 14.7\% (95\% CI, 14.5-21.6\%), and $22.4 \%$ (95\% CI, 21.0-37.0\%), respectively (Fig. 1b). The 1year, 2-year, and 3-year cumulative incidences of extensive cGVHD were $7.6 \%$ (95\% CI, 7.0-14.9\%), 11.4\% (95\% CI, $11.2-28.6 \%$ ), and $18.8 \%$ (95\% CI, 17.9-36.9\%), respectively (data not shown). On univariate analysis, no risk factors were associated with the occurrence of cGVHD (Table 2). On multivariate analysis, significant predictors of cGVHD were female donor and male recipient (hazard ratio, $60.43 ; 95 \% \mathrm{CI}, 2.72$ to $134.62 ; P=0.009)$ and a low infused $\mathrm{CD} 34^{+}$cell dose (hazard ratio, $0.54 ; 95 \% \mathrm{CI}, 0.31$ to $0.92 ; P=0.02$ ) (Table 4). Two patients with cGVHD died. Causes of death were relapse after cGVHD responded to treatment $(n=1)$ and pneumonia $(n=1)$. Eleven patients with cGVHD were alive at the last follow-up. Within 3 years after transplantation, $93.5 \%(29 / 31)$ of patients had discontinued immunosuppressive medication.

cGVHD was absent in $42(62.7 \%)$ patients $(27(69.2 \%)$ patients in the ATG group vs. 15 (53.5\%) patient in the noATG group), clinically limited in 13 patients (19.4\%; 7 (17.9\%) patients in the ATG group vs. 6 (21.4\%) patients in the no-ATG group), and clinically extensive in 15 patients (22.4\%; 6 (15.4\%) patients in the ATG group vs. 9 (32.1\%) patients in the no-ATG group) (Table 2). The 3-year cumulative incidence of cGVHD was $37.3 \%$ (95\% CI, 17.8-57.0\%) in the ATG group and $52.3 \%$ (95\% CI, 28.3-71.7\%) in the noATG group (Fig. 2c; $P=0.380$ ). The overall 3-year cumulative incidence of extensive cGVHD alone was $19.5 \%(95 \%$ CI, 5.4-40.1) in the ATG group and 33.6\% (95\% CI, 15.4$53.0)$ in the no-ATG group ( $P=0.080$; Fig. $2 \mathrm{~d})$.

cGVHD severity according to the NIH criteria was mild in 11 patients $(16.4 \%$; 7 (17.9\%) patients in the ATG group vs. 4 (14.3\%) patients in the no-ATG group), moderate in 11 patients $(16.4 \% ; 5$ (12.8\%) patients in the ATG group vs. 6 (21.4\%) patients in the no-ATG group), and severe in 6 patients $(8.9 \% ; 1(2.6 \%)$ patient in the ATG group vs. $5(17.9 \%)$ patients in the no-ATG group). Among these 28 patients, 13 patients with cGVHD had prior aGVHD ( 5 patients in the ATG group vs. 8 patients in the no-ATG group). On univariate and multivariate analyses, no-ATG was a significant risk factor for extensive cGVHD (univariate analysis: hazard ratio, 3.3; 95\% CI, 1.3-10.0; $P=0.024$; Table 3; multivariate analysis: hazard ratio, $13.0 ; 95 \% \mathrm{CI}, 1.3-128.2 ; P=0.028$; Table 4). Eight patients ( 3 patients in the ATG group vs. 5 patients in the no-ATG group) with cGVHD died due to relapse after cGVHD responded to treatment $(n=2)$ or pneumonia $(n=6)$. Twenty patients with cGVHD were alive at the last follow-up.

In the ATG group, among the 39 patients who were engrafted and survived, 3 patients (7.7\%) developed late grade 2 aGVHD. Of these, one patient had persistent (liver) late aGVHD, one patient had recurrent late aGVHD (lower gastrointestinal tract, day +103 ), and one patient had de-novo late aGVHD (skin, day +310). No patients in the ATG group with late aGVHD died. One patient in the no-ATG group had recurrent late aGVHD (lower gastrointestinal tract, day +125 ).

\section{Toxicity, TRM, and relapse}

In the ATG group, among the 40 patients who received allogeneic MSD-PBSCT, 15 (37.5\%) patients experienced infectious complications, including CMV reactivation (27.5\% [11/ 40] patients), Epstein-Barr virus reactivation (20.0\% [8/40] patients), and fungal infection (12.5\% [5/40] patients). No post-transplantation lympho-proliferative disorder was recorded (Table 2).

In the ATG group, non-relapse mortality occurred in 4 $(10.0 \%)$ of the 40 patients who received allogeneic MSD- 
Fig. 3 Cumulative incidence of TRM, relapse, OS, DFS, and GRFS after MSD-PBSCT with low-dose rATG or no rATG in combination with cyclosporine, mycophenolate, and short-term methotrexate for GVHD prophylaxis. NRM, means treatmentrelated mortality; OS, overall survival; DFS, disease-free survival; GRFS, GVHD-free relapse-free survival; GVHD, graft-versushost disease
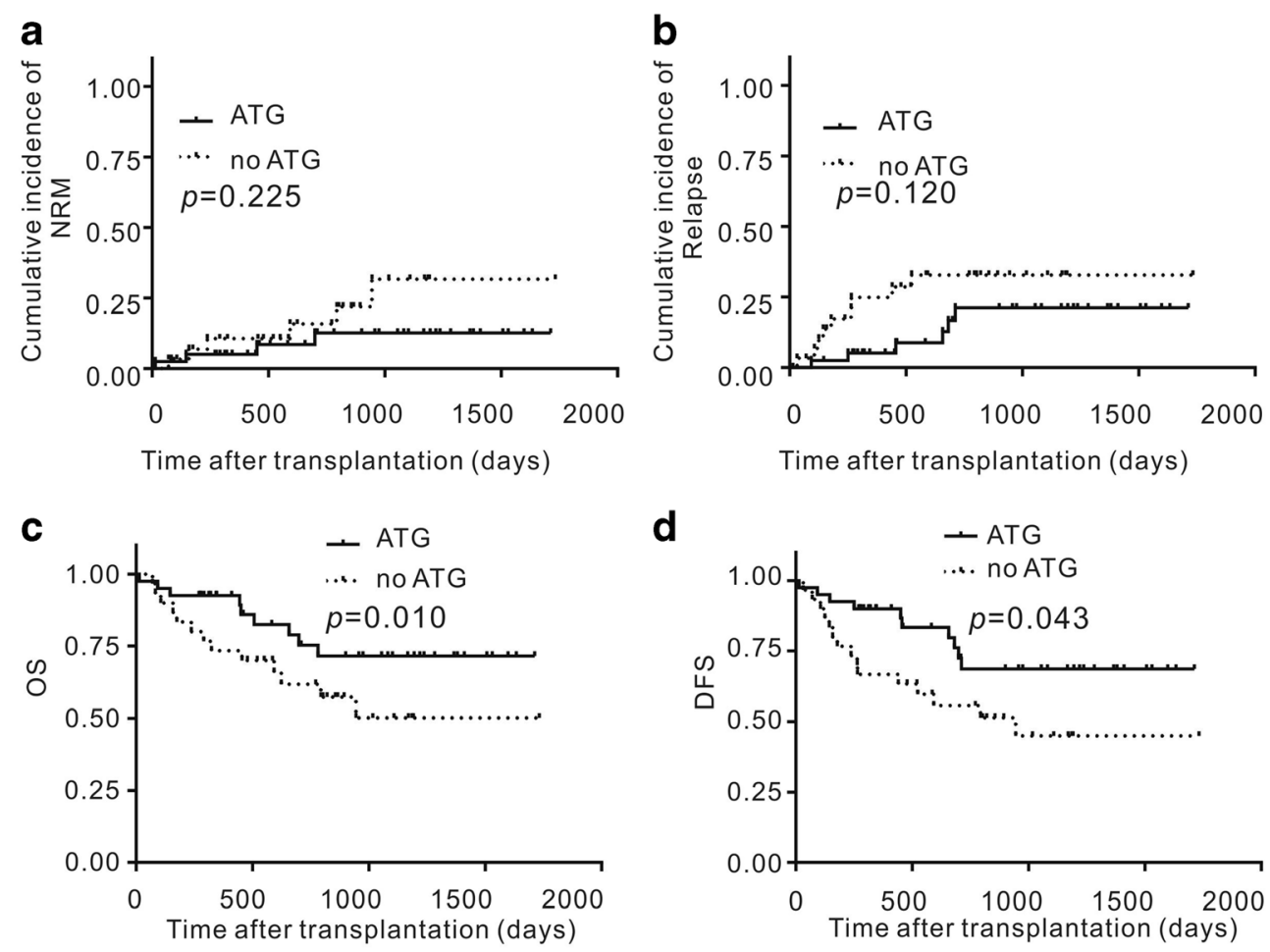

e

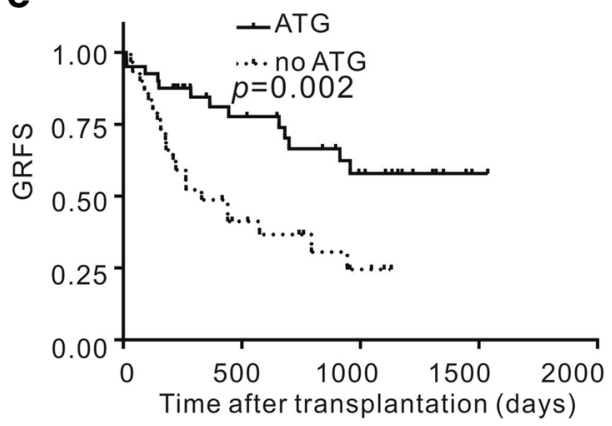

PBSCT. Among these, no patients died of GVHD, 3 patients died of pneumonia and respiratory failure, and 1 patient died of gastrointestinal hemorrhage before engraftment. The 6month, 1-year, and 2-year cumulative incidence of TRM in the ATG group was 5.8\% (95\% CI, 1.1-23.7\%), 9.5\% (95\% CI, 2.5-38.0\%), and 14.0\% (95\% CI, 13.5-39.9\%), respectively (Fig. 1c). The 2-year cumulative incidence of TRM in the ATG and no-ATG groups was not significantly different (14.0\% (95\% CI, 13.5-39.9\%) in ATG group vs. 31.6\% (95\% CI, 3.6-51.7\%) in no-ATG group; $P=0.225$ ) (Fig. 3a).

In the ATG group, 5 patients (12.5\%) who received allogeneic MSD-PBSCT relapsed at a median of 428 (93-682) days after transplantation. The 6-month, 1-year, and 2-year cumulative incidence of relapse was $6.8 \%$ (95\% CI, 2.8-24.6\%), $18.1 \%$ (95\% CI, 5.5-34.0\%), and $22.6 \%$ (95\% CI, 20.1$38.9 \%$ ), respectively (Fig. 1d). Of the five patients with relapse after transplantation, three patients were diagnosed as MDS EB-2 before transplantation, and two patients were diagnosed as T lymphoblastic lymphoma (CR1) and MLL-AF9
AML (CR1). All the relapsed patients died at a median of 87 (31-195) days after relapse, even though they were treated with salvage therapy. On univariate analysis, high-risk disease, according to the Disease Risk Index, was a risk factor for relapse (Table 3). The 2-year cumulative incidence of relapse in the ATG and no-ATG groups was not significantly different $(22.6 \%$ (95\% CI, 20.1-38.9\%) in the ATG group vs. $32.8 \%(95 \% \mathrm{CI}, 12.5-48.4 \%)$ in the no-ATG group; $P=$ 0.120 ; Fig. 3b).

\section{Survival and the quality of life}

In the ATG group, median follow-up after transplantation among survivors was 861 (271-1622) days. At the time of analysis, 31 (77.5\%) patients were still alive in CR. KaplanMeier estimates of OS 1 year, 2 years, and 3 years after transplantation were $93.1 \%$ (95\% CI, 75.1-98.2\%),73.1\% (95\% CI, 53.1-85.7\%), and 68.9\% (95\% CI, 48.2-82.7\%; Fig. $1 \mathrm{e})$; DFS 1 year, 2 years, and 3 years after transplantation were 
Table 5 Univariate and multivariate analyses of OS, GRFS, DFS, or GVHD for the risk factors of transplant outcomes in all patients

\begin{tabular}{|c|c|c|c|c|c|c|}
\hline & \multicolumn{3}{|c|}{ Univariate } & \multicolumn{3}{|c|}{ Multivariate } \\
\hline & HR & $95 \% \mathrm{CI}$ & $P$ & HR & $95 \% \mathrm{CI}$ & $P$ \\
\hline \multicolumn{7}{|l|}{ GRFS } \\
\hline \multicolumn{7}{|l|}{ Group } \\
\hline No ATG & 1.00 & & & 1.00 & & \\
\hline ATG & 0.22 & $0.20-0.70$ & 0.00 & 0.30 & $0.14-0.65$ & 0.00 \\
\hline \multicolumn{7}{|l|}{ OS } \\
\hline \multicolumn{7}{|l|}{ Group } \\
\hline No ATG & 1.00 & & & 1.00 & & \\
\hline ATG & 0.50 & $0.20-1.20$ & 0.10 & 0.16 & $0.03-0.76$ & 0.02 \\
\hline \multicolumn{7}{|l|}{ DFS } \\
\hline \multicolumn{7}{|l|}{ Group } \\
\hline No ATG & 1.00 & & & 1.00 & & \\
\hline ATG & 0.40 & $0.20-0.89$ & 0.04 & 0.04 & $0.00-0.35$ & 0.00 \\
\hline \multicolumn{7}{|c|}{ Chronic GVHD } \\
\hline \multicolumn{7}{|l|}{ Group } \\
\hline No ATG & 1.00 & & & - & & \\
\hline ATG & 0.37 & $0.05-2.58$ & 0.31 & - & - & - \\
\hline \multicolumn{7}{|c|}{ Extensive chronic GVHD } \\
\hline \multicolumn{7}{|l|}{ Group } \\
\hline No ATG & 1.00 & & & 1.00 & & \\
\hline ATG & 0.30 & $0.10-0.80$ & 0.02 & 0.02 & $0.00-0.26$ & 0.00 \\
\hline
\end{tabular}

$A T G$, anti-thymocyte globulin; $95 \% C I$, cumulative incidence $95 \% \mathrm{CI}$; $D F S$, disease-free survival; GVHD, graft-versus-host disease; GRFS, severe GVHD-free, relapse-free survival; $O S$, overall survival

Chronic, limited, and extensive grades of GVHD were defined according to the Seattle criteria

Chronic, mild, moderate, and severe grades of GVHD were defined according the NIH criteria

${ }^{*} P$ value

91.4\% (95\% CI, 75.5-97.1\%), 68.9\% (95\% CI, 48.2-82.7\%), and $68.9 \%(95 \% \mathrm{CI}, 48.2-82.7 \%$; Fig. 1F); and GRFS 1 year, 2 years, and 3 years after transplantation were $78.9 \%(95 \% \mathrm{CI}$, 60.5-89.4\%), 64.4\% (95\% CI, 44.5-78.7\%), and 54.0\% (95\% CI, 33.0-71.0\%), respectively.

The 3-year OS rate was $68.9 \%$ (95\% CI, 48.2-82.7\%) for patients in the ATG group and 50.2\% (95\% CI, 33.0-76.2\%) for patients in the no-ATG group $(P=0 \cdot 010$; Fig. 3c). The $3-$ year DFS rate was $68.9 \%(95 \% \mathrm{CI}, 48.2-82.7 \%)$ for patients in the ATG group and $44.9 \%$ (95\% CI, 28.7-70.3\%) for patients in the no-ATG group $(P=0.043$; Fig. 3d). The 3 -year GRFS rate was $54.0 \%(95 \% \mathrm{CI}, 33.0-71.0 \%)$ for patients in the ATG group and $24.4 \%(95 \%$ CI, $11.5-51.8 \%)$ for patients in the no-ATG group $(P=0 \cdot 002$; Fig. $3 \mathrm{e})$. On univariate and multivariate analyses, no-ATG was a risk factor for DFS and GRFS $(P<0.05)$ (Tables 4 and 5). On univariate and multivariate analyses, high-risk disease, according to the Disease
Risk Index, was a risk factor for poor OS or DFS in the ATG group (Table 2).

In the ATG group, health of survivors, assessed with the Karnofsky Performance Scale Index, showed 26 patients had scores of 90-100, 4 patients had a score of 80 due to cGVHD, and 1 patient had a score of 20 due to cerebral hemorrhage.

\section{T cell immune reconstitution}

In the ATG group, median lymphocyte counts, stratified into $\mathrm{CD}^{+}, \mathrm{CD}^{+}, \mathrm{CD}^{+}$, and $\mathrm{CD} 56 / \mathrm{CD}^{+} 6^{+}$subpopulations, are depicted in Fig. 4. Seventeen patients were included in immune reconstitution studies, and 14 patients had evaluable data at all time points. On day +100 , median $\mathrm{CD}^{+}, \mathrm{CD}^{+}$, $\mathrm{CD}^{+}$, and $\mathrm{CD} 56 / \mathrm{CD}^{+} 6^{+}$counts were 914 (642-1465), 189 (63-488), 686 (483-1355), and 138 (75-250), respectively. $\mathrm{CD}^{+}$cell counts were $>200 / \mu \mathrm{L}$ at day +120 and reached $330 / \mu \mathrm{L}$ on day +365 . There was no association between $\mathrm{CD}^{+}, \mathrm{CD}^{+}, \mathrm{CD}^{+}$, and $\mathrm{CD}^{+} 6^{+}$cell counts at $1,2,3,6$, and 12 months and relapse, the occurrence of GVHD, CMV/ EBV reactivation, or TRM.

On day +100 in the no-ATG and ATG groups, median $\mathrm{CD}^{+}, \mathrm{CD}^{+}, \mathrm{CD}^{+}$, and $\mathrm{CD} 56 / \mathrm{CD}^{+} 6^{+}$counts were 1600 (768-2137) and 914 (642-1465), 210 (201-274) and 189 (63-488), 878 (290-1490) and 686 (483-1355), and 315 (111-546) and $238(75-350) / \mu \mathrm{L}$, respectively. There were no differences between the two groups.

\section{Discussion}

cGVHD is the leading cause of non-relapse morbidity and mortality after allogeneic PBSCT [19]. Strategies aimed at decreasing the impact of moderate to severe cGVHD have limited efficacy, and prophylaxis is considered a superior option. This study investigated the feasibility of a $5 \mathrm{mg} / \mathrm{kg}$ total dose of rATG administered over 2 days (days -5 to -4 ) for cGVHD prophylaxis in patients receiving allogeneic MSDPBSCT. Findings showed the incidence of extensive cGVHD and severe cGVHD was low. The health of the survivors, assessed by a physician using the Karnofsky Performance Scale Index, was good, and immunosuppressive drugs were withdrawn in $93.5 \%$ of patients within 3 years after transplantation.

Optimizing the dose and timing of ATG before and after hemopoietic cell transplantation is essential to enhance patient outcomes. Kroger et al. investigated the use of ATG (rATG-F; ATG-Fresenius) at a dose of $10 \mathrm{mg} / \mathrm{kg}$ on 3,2 , and 1 days before transplantation of allogeneic peripheral blood stem cells from an HLA-identical donor in patients with acute leukemia [2]. The rate of grades $2-4$ aGVHD was $10.8 \%$, the $2-$ year cumulative incidence of cGVHD was $32.2 \%$, and the 2- 
Fig. 4 Lymphocyte counts, stratified into $\mathrm{CD}^{+}, \mathrm{CD}^{+}$, $\mathrm{CD}^{+}$, and $\mathrm{CD} 56 / \mathrm{CD} 16^{+}$ subpopulations, at days $+30,+60$, $+90,+180,+240$, and +360 after MSD-PBSCT with low-dose rATG in combination with cyclosporine, mycophenolate, and short-term methotrexate for GVHD prophylaxis
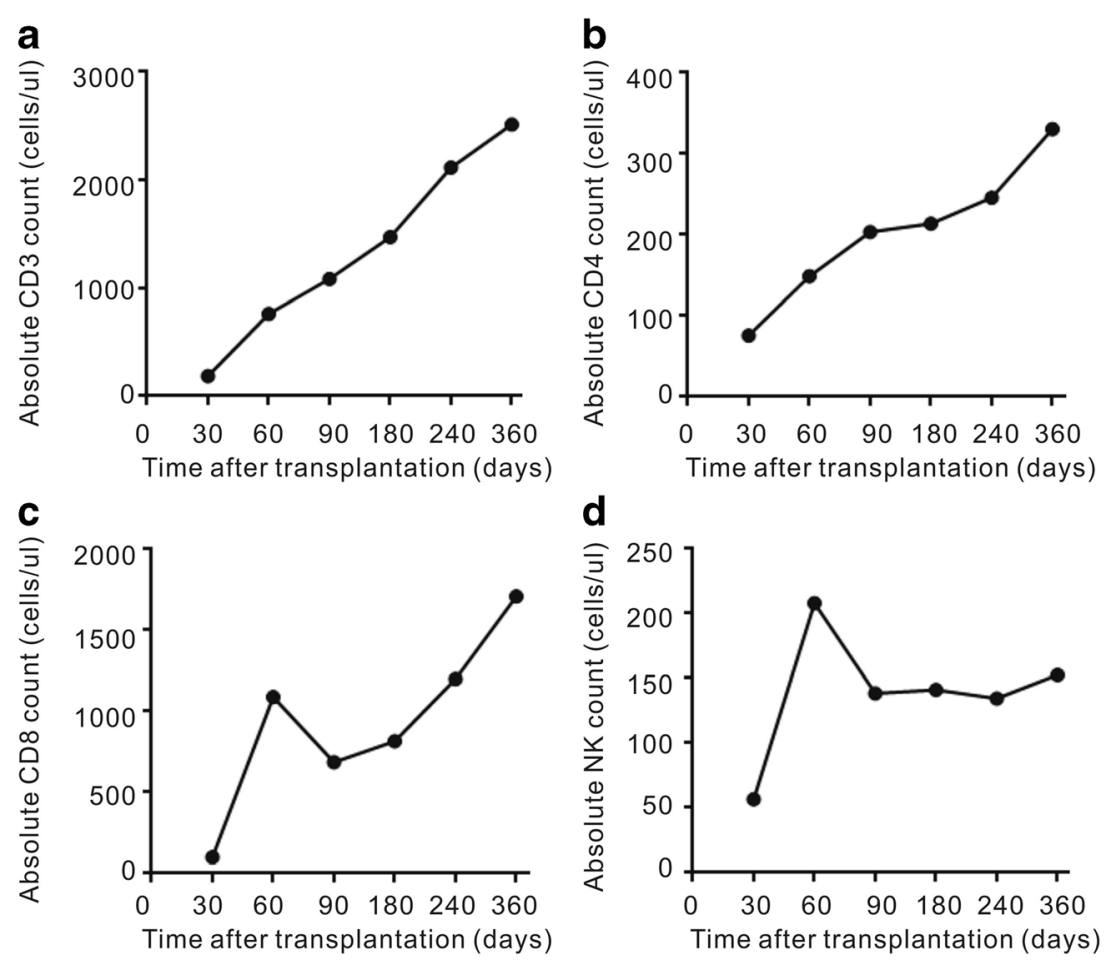

year cumulative incidence of clinical extensive cGVHD was $7.6 \%$ [2]. They used a highly purified rabbit polyclonal antihuman $\mathrm{T}$ lymphocyte immunoglobulin resulting from immunization of rabbits with the Jurkat T-lymphoblast cell line. Rubio et al. reported that the use of ATG followed by HLAidentical sibling donor allogeneic stem cell transplantation reduced the incidence of cGVHD without increasing the risk of relapse; however, this study was limited as dose, duration, brand of ATG, and GVHD prophylaxis regimen were not reported [7]. Other ATGs derived from rabbits or horses have been used in unrelated matched stem cell transplantation, but the different brands and doses are not interchangeable because of their various immunologic properties [7-11]. High exposure of ATG before transplantation resulted in significantly reduced incidence of graft failure and extensive cGVHD [20]. However, compared with exposure of ATG before transplantation, exposure of ATG after allogeneic stem cell transplantation was less effective for the prevention of grade 2-4 aGVHD and extensive cGVHD, but was essential for early immune reconstitution [21]. Socie et al. [3] found that risk of relapse did not increase with thymoglobulin doses $<6 \mathrm{mg} / \mathrm{kg}$. In the present study, rATG was received at an intravenous dose of $5 \mathrm{mg} / \mathrm{kg}$ divided over 2 days starting early on day -5 to increase exposure of rATG before transplantation and ensure low exposure of rATG after transplantation. The 2-year cumulative incidences of grade 2-4 aGVHD, grade 3-4 aGVHD, extensive cGVHD, severe cGVHD, and TRM were $30.0 \%$, $2.6 \%, 11.4 \%, 14.7 \%$, and $14.0 \%$, respectively. In patients who received MSD-PBSCT in our unit prior to January, 2013, the incidence of grade 2-4 aGVHD, grade 3-4 aGVHD, extensive cGVHD, severe cGVHD, and TRM was $13.9 \%$, $9.8 \%, 41.5 \%, 21.2 \%$, and $10.2 \%$, respectively. Although the incidence of GVHD between these two cohorts cannot be directly compared, the data imply that rATG $5 \mathrm{mg} / \mathrm{kg}$ administered on days -5 to -4 has potential to reduce the incidence of severe or extensive cGVHD without increasing the risk of relapse.

rATG contains polyclonal immunoglobulins obtained from hyper-immune sera of rabbits immunized with human thymocytes $[22,23]$. rATG administered before stem cell infusion can persist for long periods in vivo and cause $\mathrm{T}$ cell depletion of the donor graft [24], but also host immunosuppression, infection, and relapse [25]. Successful immune reconstitution after transplantation is critical for minimizing relapse and TRM [26, 27]. In a large study investigating the relationship between ATG exposure, $\mathrm{CD}^{+}{ }^{+} \mathrm{T}$ cell immune reconstitution, and clinical outcomes following pediatric cord blood transplantation (CBT), early $\mathrm{CD}^{+}{ }^{+}$immune reconstitution after CBT improved event-free survival. Early $\mathrm{CD}^{+}{ }^{+}$immune reconstitution was achieved by reducing exposure to ATG after

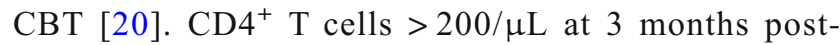
transplantation have been associated with superior OS and TRM. In the present study, we observed rapid recovery of $\mathrm{CD}^{+} \mathrm{T}$ cell and $\mathrm{CD} 4^{+} \mathrm{T}$ cells and a low rate of infectious complications and relapse. On day +100 , median $\mathrm{CD}^{+}$and $\mathrm{CD}^{+} \mathrm{T}$ cell counts were 1117 and $104 / \mu \mathrm{L}$. CD4 ${ }^{+}$cell counts were $>200 / \mu \mathrm{L}$ at day +120 and reached $330 / \mu \mathrm{L}$ on day +365 .

In summary, these data suggest that rATG for GVHD prophylaxis is tolerable and efficacious at a $5 \mathrm{mg} / \mathrm{kg}$ total dose administered over 2 days (day -5 to -4 ) in patients receiving 
allogeneic MSD-PBSCT. Further studies are required to evaluate the active rATG serum concentrations and the optimal prophylactic strategy in this patient population.

Funding information This work was partially supported by grants from the Beijing Nova Program (2011114), the National Natural Science Foundation of China (Nos. 81270610, 81770203, and 30800482), the Beijing Natural Science Foundation of China (Nos. 7102147, 7172200, and 7132217), the Capital's Funds for Health Improvement and Research (No. 2016-1-4082), the Fund Sponsorship of the Capital Public Health Project for DH Liu, National Key Clinical Specialized Military Construction Project (Clinical Medicine), and Hainan Provincial Natural Science Foundation of China (818MS157).

\section{Compliance with ethical standards}

Conflict of interest The authors declare that they have no conflict of interest.

Ethical approval This study was approved by the Ethics Committee of the Chinese People's Liberation Army (PLA) General Hospital. All procedures performed in studies involving human participants were in accordance with the ethical standards of the institutional and/or national research committee and with the 1964 Helsinki declaration and its later amendments or comparable ethical standards.

Informed consent Informed consent was obtained from all individual participants included in the study.

Open Access This article is licensed under a Creative Commons Attribution 4.0 International License, which permits use, sharing, adaptation, distribution and reproduction in any medium or format, as long as you give appropriate credit to the original author(s) and the source, provide a link to the Creative Commons licence, and indicate if changes were made. The images or other third party material in this article are included in the article's Creative Commons licence, unless indicated otherwise in a credit line to the material. If material is not included in the article's Creative Commons licence and your intended use is not permitted by statutory regulation or exceeds the permitted use, you will need to obtain permission directly from the copyright holder. To view a copy of this licence, visit http://creativecommons.org/licenses/by/4.0/.

\section{References}

1. Zeiser R, Blazar BR (2017) Pathophysiology of chronic graftversus-host disease and therapeutic targets. N Engl J Med 377: 2565-2579

2. Kroger N, Solano C, Wolschke C et al (2016) Antilymphocyte globulin for prevention of chronic graft-versus-host disease. $\mathrm{N}$ Engl J Med 374:43-53

3. Socie G, Schmoor C, Bethge WA et al (2011) Chronic graft-versushost disease: long-term results from a randomized trial on graftversus-host disease prophylaxis with or without anti-T-cell globulin ATG-Fresenius. Blood 117:6375-6382

4. Li HH, Li F, Gao CJ et al (2017) Similar incidence of severe acute GVHD and less severe chronic GVHD in PBSCT from unmanipulated, haploidentical donors compared with that from matched sibling donors for patients with haematological malignancies. Br J Haematol 176:92-100
5. Huang W, Yu L, Cao T, Li Y, Liu Z, Li H, Bo J, Zhao Y, Jing Y, Wang S, Zhu H, Dou L, Wang Q, Gao C (2016) The efficacy and safety of rabbit anti-thymocyte globulin vs rabbit anti-Tlymphocyte globulin in peripheral blood stem cell transplantation from unrelated donors. Leuk Lymphoma 57:355-363

6. Bonifazi F, Bandini G, Arpinati M, Tolomelli G, Stanzani M, Motta MR, Rizzi S, Giudice V, Dan E, Massari E, Tazzari P, Bontadini A, Pagliaro P, Baccarani M (2012) Intensification of GVHD prophylaxis with low-dose ATG-F before allogeneic PBSC transplantation from HLA-identical siblings in adult patients with hematological malignancies: results from a retrospective analysis. Bone Marrow Transplant 47:1105-1111

7. Rubio MT, D'Aveni-Piney M, Labopin M et al (2017) Impact of in vivo T cell depletion in HLA-identical allogeneic stem cell transplantation for acute myeloid leukemia in first complete remission conditioned with a fludarabine iv-busulfan myeloablative regimen: a report from the EBMT Acute Leukemia Working Party. J Hematol Oncol 10:31

8. Chang YJ, Wang Y, Mo XD, Zhang XH, Xu LP, Yan CH, Chen H, Chen YH, Chen Y, Han W, Wang FR, Wang JZ, Liu KY, Huang XJ (2017) Optimal dose of rabbit thymoglobulin in conditioning regimens for unmanipulated, haploidentical, hematopoietic stem cell transplantation: long-term outcomes of a prospective randomized trial. Cancer 123:2881-2892

9. Su RJ, Green R, Chen M (2018) Enumeration of bone marrow plasmacytoid dendritic cells by multiparameter flow cytometry as a prognostic marker following allogeneic hematopoietic stem cell transplantation. Blood Cells Mol Dis 69:107-112

10. Wang Y, Fu HX, Liu DH, Xu LP, Zhang XH, Chang YJ, Chen YH, Wang FR, Sun YQ, Tang FF, Liu KY, Huang XJ (2014) Influence of two different doses of antithymocyte globulin in patients with standard-risk disease following haploidentical transplantation: a randomized trial. Bone Marrow Transplant 49:426-433

11. Mohty M, Ho AD (2011) In and out of the niche: perspectives in mobilization of hematopoietic stem cells. Exp Hematol 39:723-729

12. Zhao XF, Mao XF, Wan DM, Liu W (2014) Modified busulfan and cyclophosphamide conditioning regimen for allogeneic hematopoietic stem cell transplantation in the treatment of patients with hematologic malignancies. Transplant Proc 46:1531-1535

13. Yosupov N, Haimov H, Juodzbalys G (2017) Mobilization, isolation and characterization of stem cells from peripheral blood: a systematic review. J Oral Maxillofac Res 8:e1

14. Bontems S, Boreux R, Capraro V, Huynen P, Descy J, Melin P, Hayette MP, Meex C (2019) Evaluation of the Abbott RealTime quantitative $\mathrm{CMV}$ and $\mathrm{EBV}$ assays using the maxCycle protocol in a laboratory automation context. J Virol Methods

15. Arora M, Klein JP, Weisdorf DJ, Hassebroek A, Flowers ME, Cutler CS, Urbano-Ispizua A, Antin JH, Bolwell BJ, Boyiadzis M, Cahn JY, Cairo MS, Isola L, Jacobsohn DA, Jagasia M, Klumpp TR, Lee SJ, Petersdorf EW, Santarone S, Gale RP, Schouten HC, Spellman S, Wingard JR, Horowitz MM, Pavletic SZ (2011) Chronic GVHD risk score: a Center for International Blood and Marrow Transplant Research analysis. Blood 117: 6714-6720

16. Lee SE, Cho BS, Kim JH, Yoon JH, Shin SH, Yahng SA, Eom KS, Kim YJ, Kim HJ, Lee S, Min CK, Cho SG, Kim DW, Lee JW, Min WS, Park CW (2013) Risk and prognostic factors for acute GVHD based on NIH consensus criteria. Bone Marrow Transplant 48:587592

17. Rihn C, Cilley J, Naik P, Pedicano AV, Mehta J (2004) Definition of myeloid engraftment after allogeneic hematopoietic stem cell transplantation. Haematologica 89:763-764

18. Armand P, Kim HT, Logan BR, Wang Z, Alyea EP, Kalaycio ME, Maziarz RT, Antin JH, Soiffer RJ, Weisdorf DJ, Rizzo JD, Horowitz MM, Saber W (2014) Validation and refinement of the 
Disease Risk Index for allogeneic stem cell transplantation. Blood 123:3664-3671

19. Bonifazi F, Solano C, Wolschke C, Sessa M, Patriarca F, Zallio F, Nagler A, Selleri C, Risitano AM, Messina G, Bethge W, Herrera P, Sureda A, Carella AM, Cimminiello M, Guidi S, Finke J, Sorasio R, Ferra C, Sierra J, Russo D, Benedetti E, Milone G, Benedetti F, Heinzelmann M, Pastore D, Jurado M, Terruzzi E, Narni F, Völp A, Ayuk F, Ruutu T, Kröger N (2019) Acute GVHD prophylaxis plus ATLG after myeloablative allogeneic haemopoietic peripheral blood stem-cell transplantation from HLA-identical siblings in patients with acute myeloid leukaemia in remission: final results of quality of life and long-term outcome analysis of a phase 3 randomised study. Lancet Haematol 6:e89-e99

20. Admiraal R, Lindemans CA, van Kesteren C, Bierings MB, Versluijs AB, Nierkens S, Boelens JJ (2016) Excellent T-cell reconstitution and survival depend on low ATG exposure after pediatric cord blood transplantation. Blood 128:2734-2741

21. Admiraal R, van Kesteren C, Jol-van der Zijde CM, Lankester AC, Bierings MB, Egberts TC, van Tol MJ, Knibbe CA, Bredius RG, Boelens JJ (2015) Association between anti-thymocyte globulin exposure and CD4+ immune reconstitution in paediatric haemopoietic cell transplantation: a multicentre, retrospective pharmacodynamic cohort analysis. Lancet Haematol 2: e194-e203
22. Storek J, Mohty M, Boelens JJ (2015) Rabbit anti-T cell globulin in allogeneic hematopoietic cell transplantation. Biol Blood Marrow Transplant 21:959-970

23. Nishihori T, Al-Kadhimi Z, Hamadani M, Kharfan-Dabaja MA (2016) Antithymocyte globulin in allogeneic hematopoietic cell transplantation: benefits and limitations. Immunotherapy 8:435447

24. Zhang P, Curley CI, Mudie K, Nakagaki M, Hill GR, Roberts JA, Tey SK (2019) Effect of plasmapheresis on ATG (thymoglobulin) clearance prior to adoptive $\mathrm{T}$ cell transfer. Bone Marrow Transplant

25. Theurich S, Fischmann H, Shimabukuro-Vornhagen A, Chemnitz JM, Holtick U, Scheid C, Skoetz N, von Bergwelt-Baildon M (2012) Polyclonal anti-thymocyte globulins for the prophylaxis of graft-versus-host disease after allogeneic stem cell or bone marrow transplantation in adults. Cochrane Database Syst Rev:Cd009159

26. Chang YJ, Zhao XY, Huang XJ (2014) Immune reconstitution after haploidentical hematopoietic stem cell transplantation. Biol Blood Marrow Transplant 20:440-449

27. Scheinberg P, Nunez O, Weinstein B, Scheinberg P, Biancotto A, Wu CO, Young NS (2011) Horse versus rabbit antithymocyte globulin in acquired aplastic anemia. N Engl J Med 365:430-438

Publisher's note Springer Nature remains neutral with regard to jurisdictional claims in published maps and institutional affiliations. 